\title{
NUMERICAL INVESTIGATION ON HEAT SINK BY COMPUTATIONAL FLUID DYNAMICS (CFD)
}

\author{
Jeevaraj S \\ Assistant Professor, Department of Mechanical Engineering, Bheemanna Khandre Institute of Technology, Bhalki, Dist: \\ Bidar State: Karnataka
}

\begin{abstract}
The forced-air cooling technique, one of the effective methods for thermal management of electronic equipment cooling, is commonly used in a conventional-size heat sink. Conventional or mini sized heat sinks are commonly used in many industrial applications as cooling devices, because of their easy serviceability, high reliability, simplicity in the mechanism of heat transfer and ease of testing. In this paper heat sink is designed and investigated for different velocity variation at the inlet to select appropriate fan to cool the heat sink and also effect of ambient conditions on the heat sink are studied. Finally the results are compared with the Computational Fluid Dynamics software FLUENT.
\end{abstract}

Keywords: Heat sink, fins, forced air cooling, Computational Fluid Dynamics analysis.

\section{INTRODUCTION}

Generally heat sink essentially consists of a flat base and an array of fins to increase the surface area so that that the heat dissipation rate is also increased. These are devices that enhance heat dissipation from a hot surface, usually the case of a heat generating component, to a cooler ambient, usually air which is assumed to be the cooling fluid. In most situations, heat transfer across the interface between the solid surface and the coolant air is the least efficient within the system, and the solid-air interface represents the greatest barrier for heat dissipation. A heat sink lowers this barrier mainly by increasing the surface area that is in direct contact with the coolant. This allows more heat to be dissipated and/or lowers the device operating temperature. The primary purpose of a heat sink is to maintain the device temperature below the maximum allowable temperature specified by the device manufacturers.

IBM built the milestone computer in 1944 which used airconditioned hallways to cool its 18000 vacuum tubes, 500000 soldered joints. When BELL labs developed transistor in 1947, most scientist thought that the burden of cooling electronics would be eliminated. The theoretical basis of the methods currently used to design heat sinks were initially described by Kays and London [1964] and by Kern and Kraus [1972]. Poulikakos and Bejan [1982] have published extensively in the area of optimization of a heat sink using an entropy minimization approach. Amongst the recent literature, the work of Culham and Muzychka [2000] extended Bejan's work to include the optimization of a plate fin heat sink together with the pressure drop effects associated with viscous dissipation. Bar-Cohen and Jelinek [1985] and Yeh and Chang [1995] studied the cooling effect with the least material optimization for the fin array heat sink by using mathematical formulation.
Leung and Probert [1989] used experimental measurements to find the optimum separation for vertical rectangular fins protruding from a vertical rectangular base. Sparrow and Larson [1982] experimentally measured heat transfer coefficients for pin-fin arrays when the airflow initially enters the array perpendicular to the fin base. Recently, Lee [1995] presented a simple method to determine the flow velocity between fins. Minakami et al. [1996] carried out experiments and numerical studies to evaluate the effect of flow guide vanes on an air-cooling pin-fin array heat sink. The pin-fin array used in the experiments was made of thin square copper pins. Kobus and Oshio [2005] developed a theoretical model as well as experimental study for predicting the thermal performance of pin-fin array heat sinks under conditions of mixed convection for the case of impinging flow on vertical arrays and later included radiation in their analysis [2006]. Charnwit Udomsakdigool et al. [2007] experimentally investigated the heat sink performance of a new rectangular fins array for Thermoelectric Dehumidifier varying the operating conditions like the distance between the fan and the fins, heat flux applied to the sink, and fan voltage. Bhramara et al.[2008]had studied, the performance of a desktop heat sink under forced convective conditions of air cooling using ANSYS-FLOTRAN. The results were compared with experimental data obtained using the aluminum desk top computer. While there have been continued advances in high heat-flux technologies, commercial and consumer oriented systems continue to focus on air cooling for reasons of reliability, cost, and portability.

In this regard a heat sink is designed and investigated for different velocity variation at the inlet to select appropriate fan to cool the heat sink and also effect of ambient conditions on 
the heat sink are studied. Finally the results are compared with the Computational Fluid Dynamics software FLUENT.

\section{DETERMINATION OF VOLUME OF HEAT SINK}

Table1 shows approximate ranges of volumetric thermal resistance of a typical heat sink under different flow conditions.

Table1: Range of volumetric thermal resistance

\begin{tabular}{|c|c|c|}
\hline Flow condition $\mathbf{~ m} / \mathbf{s}$ & \multicolumn{2}{|c|}{$\begin{array}{l}\text { Volumetric Resistance } \\
\mathbf{c m}^{\mathbf{3}}{ }^{\circ} \mathbf{C} / \mathbf{W}\left(\mathbf{i n}^{\mathbf{3}}{ }^{\circ} \mathbf{C} / \mathbf{W}\right)\end{array}$} \\
\hline Natural convection & $500-800$ & $(30-50)$ \\
\hline $1.0(200)$ & $150-250$ & $(10-15)$ \\
\hline $2.5(500)$ & $80-150$ & $(5-10)$ \\
\hline $5.0(1000)$ & $50-80$ & $(3-5)$ \\
\hline
\end{tabular}

The smaller values shown above correspond to a heat sink volume of approximately 100 to $200 \mathrm{~cm}^{3}\left(5\right.$ to $\left.10 \mathrm{in}^{3}\right)$ and the larger ones to roughly $1000 \mathrm{~cm}^{3}\left(60 \mathrm{in}^{3}\right)$.

\section{DESIGN AND ANALYSIS OF A HEAT SINK}

The aluminum heat sink is considered for the analysis. It has a thermal conductivity of $205 \mathrm{~W} / \mathrm{m} \mathrm{K}$. Its ease of fabrication and light weight make it excellent material for forming long individual fins.

\subsection{Building the Model}

Depending on the dimensions of the base plate, 3-D Cartesian co-ordinates of brick is created. With given dimensions one fin is created and it is positioned at the appropriate location using the option move and translate. 9 more fins are created using the option copy and then fluid zones are created in between the fins and base plate. Finally, twenty volumes, one comprising base plate, ten volumes being fins and reaming nine being fluid volumes, the volumes between the fins and the base plate are formed.

\subsection{Grid Generation}

First, the fin volumes are discretised, using volume mesh technique. A HEX uniform type of mesh elements used in the grid. A similar approach is used in the meshing of the volume between the fins but with non uniform size elements are used. Near the walls of the fin fine size of elements are used and at the middle courser size elements are used. Finally base plate is meshed with HEX. The overall mesh of the geometry consists of 4, 17,560 elements of which the equi-skew ness of the worst element is 0.0471605 .

\subsection{Defining Material Properties}

The properties of air at $57.5^{\circ} \mathrm{C}$ and those of Aluminum at room temperature are given as inputs in the material properties window under fluid and solid categories

\section{BOUNDARY CONDITIONS:}

Boundary conditions are entered as follows:

a. Base plate, Fins (solid): - Aluminium properties are assigned.

b. Base top(wall): Base top is receiving heat from the chip, so heat flux is applied on the base top

c. Fin bottom, Front face, Left, Right, Rear face (Walls): Heat transfer to surrounding atmosphere by convection

d. Inlet (velocity inlet): Air enters into the Heat sink with $12 \mathrm{~m} / \mathrm{s}$ in the negative $\mathrm{z}$-direction according to the geometry.

e. Outlet (Pressure Outlet): After passing through the heat sink air enters into atmosphere, so at outlet atmospheric pressure is assumed

After applying the above boundary conditions. Simulation is performed under steady state conditions till the convergence is reached.

\section{THEORETICAL SOLUTION PROCEDURE}

\subsection{Assumptions}

Ambient temperature of air $\left(\mathrm{t}_{\mathrm{a}}\right)=45^{\circ} \mathrm{C}$

Velocity of air $(\mathrm{v})=12 \mathrm{~m} / \mathrm{sec}$

Thickness of the fin $(t)=1.5 \mathrm{~mm}$

Length of the fin $=0.146 \mathrm{~m}$

$$
\text { Average temperature } \begin{aligned}
\left(\mathrm{t}_{\mathrm{f}}\right) & =\left(\frac{\mathrm{ts}+\mathrm{ta}}{2}\right) \\
& =(70+45) / 2 \\
& =57.5^{\circ} \mathrm{C}
\end{aligned}
$$

The properties of dry air at $57.5^{\circ} \mathrm{C}$

\subsection{Determining the Heat Transfer Coefficient}

\section{(Natural Convection)}

Using the following equations

$$
\begin{gathered}
\mathbf{R a}=\left[\mathbf{P r} \mathbf{g}^{*} \boldsymbol{\beta}^{*}(\mathbf{T s}-\mathbf{T a})^{*} \mathbf{L}^{3}\right] / \mathbf{v}^{2} \\
\mathrm{~S}_{\mathrm{opt}}=2.174 * L / R a^{0.25} \\
\mathrm{Nu}=\frac{h^{*} s}{k}=\left[\frac{576 * L}{R a * s}+\frac{0.1693 * L}{s}\right]^{0.5}
\end{gathered}
$$


Determination of area required:

$$
\mathrm{Q}=\mathrm{h} \text { A (Ts-Ta) }
$$

Design of Forced Convection Cooling System For Cooling High Power Electronics Systems

Determining the type of flow:

$$
\text { Reynolds's number }\left(\operatorname{Re}_{\mathrm{L}}\right)=(\rho \vee \mathrm{L}) / \mu
$$

Determining the heat transfer co-efficient $(\mathrm{h})$ :

To find the NUSSELT number we use the formula given below for forced convection.

$$
\begin{gathered}
\mathrm{Nu}=7.54+\left(.03 *\left(\left(\mathrm{D}_{\mathrm{h}}\right) / \mathrm{L}\right) * \operatorname{Re}_{\mathrm{Dh}} * \operatorname{Pr}\right) /\left(1+0.016 *\left\{\left(\left(\mathrm{D}_{\mathrm{h}}\right) / \mathrm{L}\right) *\right.\right. \\
\left.\left.\operatorname{Re}_{\mathrm{Dh}} * \operatorname{Pr}\right\}{ }^{2 / 3}\right) \\
\mathrm{m}=\rho * \mathrm{~S}_{\mathrm{opt}} * \mathrm{H} *(\mathrm{n}-1) * \mathrm{~V} \\
\mathrm{Q}=\mathrm{m} * \mathrm{Cp} *\left(\mathrm{t}_{\max }-\mathrm{t}_{\mathrm{amb}}\right)
\end{gathered}
$$

\begin{tabular}{|c|c|c|c|c|}
\hline $\begin{array}{c}\text { Ambient } \\
\text { Temperat } \\
\text { ure } \\
\text { (ta) }{ }^{\circ} \mathrm{C}\end{array}$ & $\begin{array}{c}\begin{array}{c}\text { Area } \\
\text { of } \\
\text { Sink } \\
(A)( \\
\left.\mathbf{m}^{2}\right)\end{array}\end{array}$ & $\begin{array}{l}\text { Heig } \\
\text { ht of } \\
\text { fins } \\
\text { (H) } \\
\text { (m) }\end{array}$ & $\begin{array}{c}\begin{array}{c}\text { Coefficient } \\
\text { of }\end{array} \\
\text { convective } \\
\text { heat } \\
\text { transfer } \\
{\text { Watt } / \mathbf{m}^{2}}^{2} \\
{ }^{\circ} \mathbf{C}(\mathbf{h})\end{array}$ & $\begin{array}{c}\text { Final } \\
\text { tempera } \\
\text { ture }(\Delta t) \\
{ }^{\circ} \mathrm{C}\end{array}$ \\
\hline 30 & 0.084 & .010 & 62.51 & 47.86 \\
\hline 35 & 0.09 & .010 & 61.98 & 51.6 \\
\hline 40 & 0.105 & .013 & 61.07 & 53.6 \\
\hline 45 & 0.105 & .017 & 60.68 & 55.25 \\
\hline 50 & .0126 & .021 & 60.12 & 58.61 \\
\hline
\end{tabular}

\section{THEORETICAL RESULTS}

Table2 shows different values keeping inlet velocity at $12 \mathrm{~m} / \mathrm{s}$

Table3 shows different values keeping ambient temperature at $45^{\circ} \mathrm{C}$

\begin{tabular}{|c|c|c|c|}
\hline $\begin{array}{c}\text { Velocity of } \\
\mathbf{a i r}(\mathbf{v}) \\
(\mathbf{m} / \mathbf{s e c})\end{array}$ & $\begin{array}{c}\text { Area of } \\
\text { sink (A) } \\
\left(\mathbf{m}^{\mathbf{2}}\right)\end{array}$ & $\begin{array}{c}\text { Height of } \\
\text { fins (H) } \\
(\mathbf{m})\end{array}$ & $\begin{array}{c}\text { Coefficient of } \\
\text { convective heat } \\
\text { transfer } \\
\text { Watt }^{\mathbf{2}} \mathbf{~}^{\mathbf{}} \mathbf{C}(\mathbf{h})\end{array}$ \\
\hline 4 & 0.105 & 0.029 & 44.44 \\
\hline 6 & 0.105 & 0.024 & 49.94 \\
\hline 8 & 0.105 & 0.0209 & 54.56 \\
\hline 10 & 0.105 & 0.018 & 58.64 \\
\hline 12 & 0.105 & 0.017 & 60.68 \\
\hline 14 & 0.105 & 0.016 & 63.54 \\
\hline
\end{tabular}

\section{RESULTS AND DISCUSSIONS}

Results obtained using FLUENT software and theoretical calculations of the heat sink are compared.

\subsection{Variations of the Temperature along the Sink}

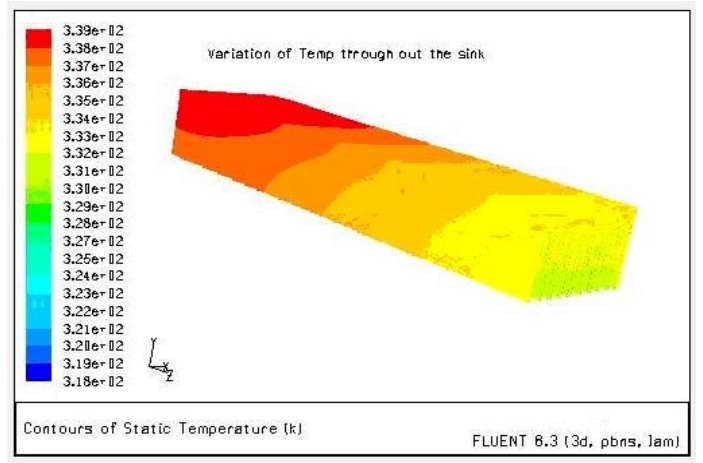

Fig1: Variations of the Temperature along the Sink

The figure 1 represents the temperature variation along the sink using FLUENT CFD solver. Here the sink receives heat from the chip which is placed at the top so more temperature is observed at the top of the sink i.e at the base plate. At the inlet of the sink the temperature is less compare to the rear end of the sink because the front end of the sink is exposed to the cold inlet air. At the bottom of the sink temperature is less compared to the top of the fin because due to conduction heat is transferred from base to fins and from fins heat is transferred to air by convection.

\subsection{Variation of the Temperature at the Inlet, Middle and Outlet of the Sink}

The figure 2 represents the temperature of the sink and air at inlet, middle and outlet sections. It is observed that minimum temperature of the sink and air is at inlet section and maximum at the outlet section due conduction and convection.

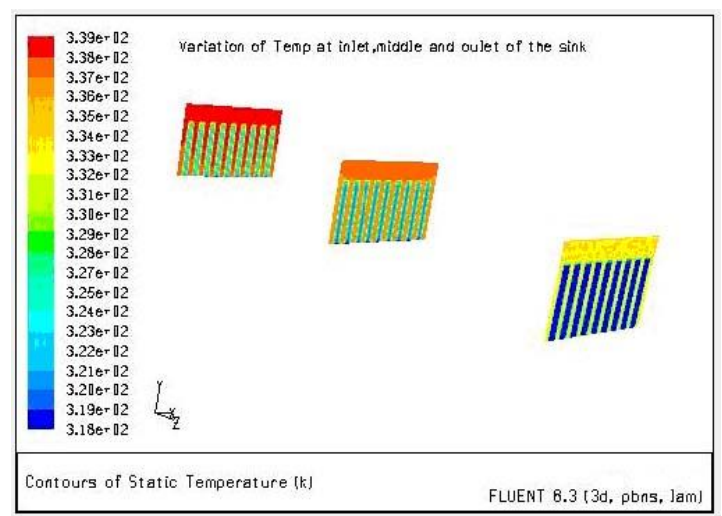

Fig2: Variation of the Temperature at the Inlet, Middle and Outlet of the Sink 


\subsection{Variation of Temperature on Top of the Base Plate}

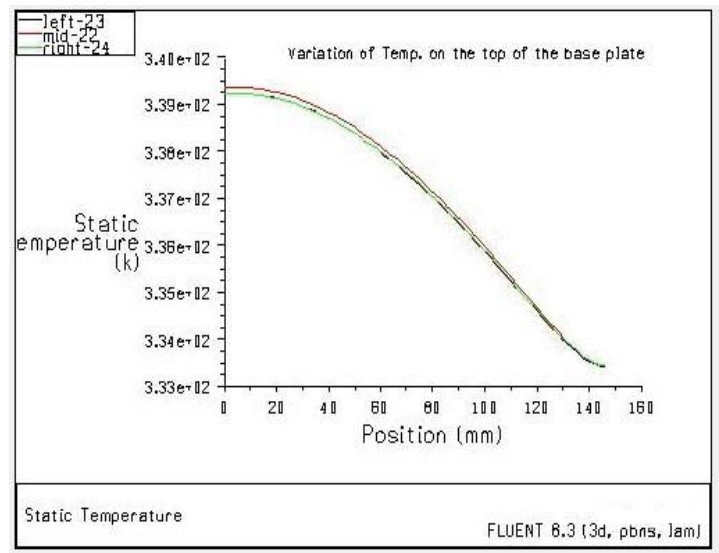

Fig3: Variation of Temperature on Top Of the Base Plate

The above figure 3 represents the variation temperature on the top of the base plate along the depth of the plate. The temperature is minimum at the right and left side of the top of base plate and it is maximum at the mid of the base plate due to more heat transfer at the sides of base plate due convection

\subsection{Variation of Max temp on the sink with Velocity of}

\section{Inlet Air at $45^{\circ} \mathrm{C}$}

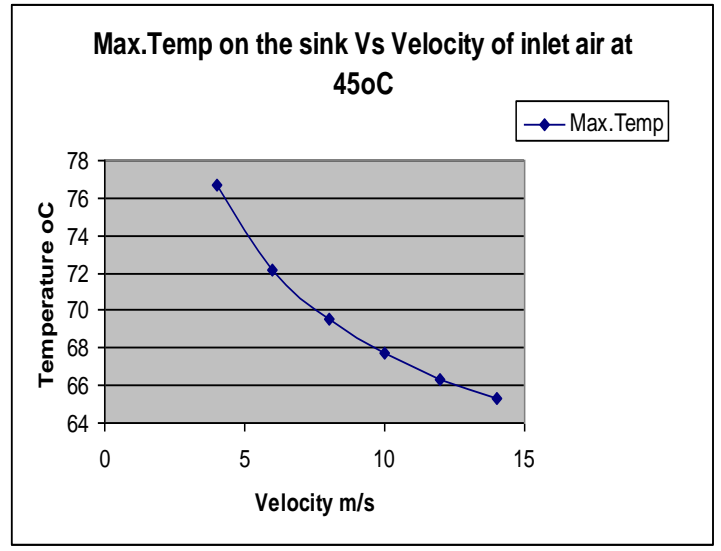

Graph1: Variation of Max temp on the sink with Velocity of inlet air at $45^{\circ} \mathrm{C}$

The above graph1 represents the Maximum temperature on the sink for different inlet velocities if inlet air. As the inlet velocity increases the maximum temperature on the sink decreases because more heat is transferred to the air. At 4 and $6 \mathrm{~m} / \mathrm{s}$ the maximum temperature on the sink is exceeding the maximum design temperature $70^{\circ} \mathrm{c}$. The sink should be operated above $6 \mathrm{~m} / \mathrm{s}$ inlet temperature if the ambient temperature is $45^{\circ} \mathrm{c}$.

\subsection{Comparison of Maximum Temperature for} Different Ambient Inlet Temp using Fluent and

\section{Theoretical Values}

The following graph2 shows the variation of maximum sink temperature for various inlet temperatures .The maximum temperature obtained using theoretical calculations are less compared to Fluent calculations because assumptions are made for theoretical calculations.

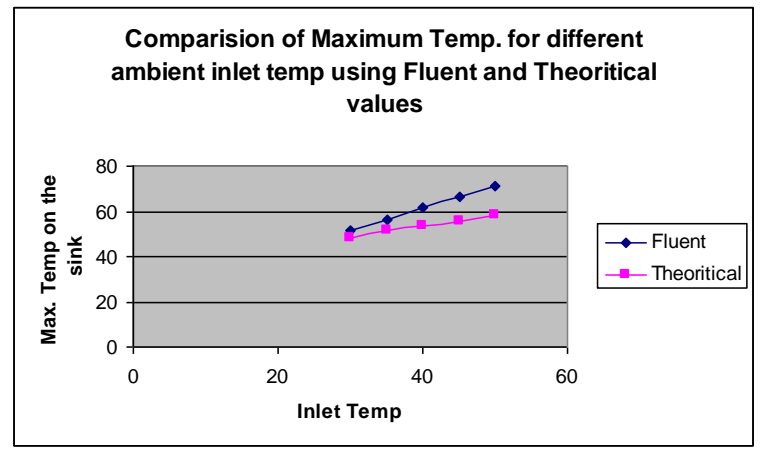

Graph2: Comparison of maximum Temp. For different ambient inlet temp

7.6 Variations of Temperature on the Sink for Different Inlet Air Temperature at a Velocity $=12 \mathrm{~m} / \mathrm{s}$

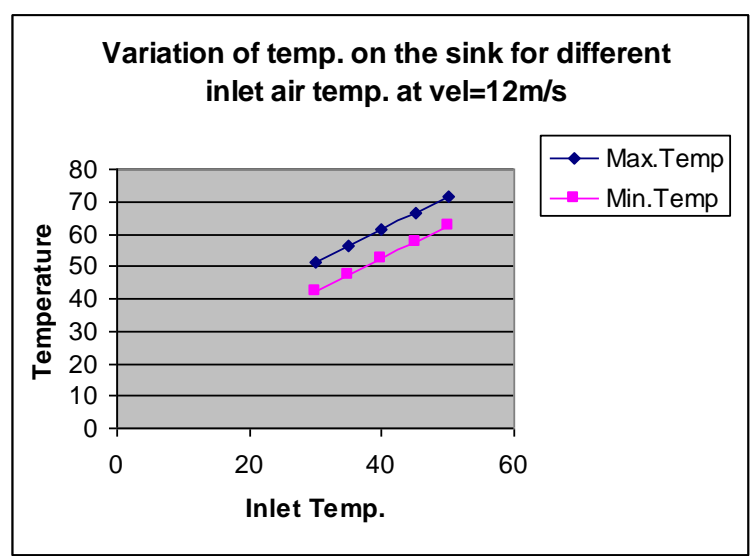

Graph3: Variations of temperature on the sink for different inlet air temperature at a velocity $=12 \mathrm{~m} / \mathrm{s}$

The above graph3 shows the variation of the maximum and minimum temperatures of the sink at constant air velocity of $12 \mathrm{~m} / \mathrm{s}$ and varying inlet temperature. As the inlet temperature of the ambient air increases the maximum and minimum temperatures on the sink also increases. All the theoretical values are below $70^{\circ} \mathrm{C}$ but at $50^{\circ} \mathrm{C}$ inlet temperature, the maximum sink temperature just exceeds above $70^{\circ} \mathrm{C}$ in Fluent. 


\subsection{Comparison of Temperature on the Surface of}

\section{Heat Sink using theoretical and Fluent Software}

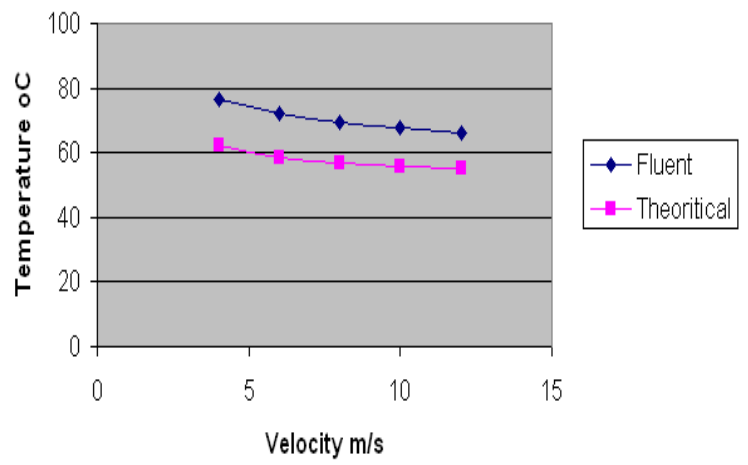

Graph4: Comparison of temperature on the surface of heat sink

The above graph 4 shows the comparison of theoretical and Fluent calculations for maximum temperature on the sink. All the values obtained theoretically are below $70^{\circ} \mathrm{C}$ but at $4 \mathrm{~m} / \mathrm{s}$ and $6 \mathrm{~m} / \mathrm{s}$ the maximum surface temperature exceeds $70^{\circ} \mathrm{C}$ using Fluent.

\section{CONCLUSIONS}

Comparative studies of the design parameters of the heat sink are carried using Theoretical and CFD analysis and the following conclusions were made.

- The selected material for heat sink is aluminum because of its high thermal conductivity and it's lightweight.

- In order to optimize the chip usage parametric study is carried out by varying the ambient temperature, keeping the inlet velocity constant. It is found that at $12 \mathrm{~m} / \mathrm{s}$ inlet velocity, the maximum ambient temperature allowed to operate the chip is $45^{\circ} \mathrm{C}$.

- In order to optimize the chip usage, parametric study is carried out by varying the inlet velocity, keeping the ambient temperature as constant at $45^{\circ} \mathrm{C}$. It is found that at $45^{\circ} \mathrm{C}$ ambient temperature, the minimum velocity of air allowed to operate the chip is $4 \mathrm{~m} / \mathrm{s}$.

- Theoretical values and the values obtained from fluent are compared. It is found that maximum temperature values using Fluent are slightly more than the theoretical values because while calculating the theoretical values assumptions are made.

- This method took less time as compared to the theoretical procedure.

- The CFD results are close to theoretical values.

\section{DATA FOR REFERENCE}

AMD Athlon, Athlon 64, Opteron, Duron and Sempron All Slot A CPUs (Athlon classic, Athlon Thunderbird) $70^{\circ} \mathrm{C}$ Athlon Socket A up to $1 \mathrm{GHz}$, Duron up to $1.3 \mathrm{GHz} \quad 90^{\circ} \mathrm{C}$ Athlon "Thunderbird" Socket A $1.1 \mathrm{GHz}$ or more $\quad 95^{\circ} \mathrm{C}$ Athlon MP $1.33 \mathrm{GHz}$ or more Athlon XP up to $2100+\quad 90^{\circ} \mathrm{C}$

Athlon XP 2200+ and faster

Duron "Applebred" 1.4G and faster AMD Opteron $95^{\circ} \mathrm{C}$

$70^{\circ} \mathrm{C}$ depending on model

Athlon 64, 64FX, Sempron

Most models

some Socket 939 Athlon 64 models

Athlon 64 X2 (dual core)

$85^{\circ} \mathrm{C}$

$85^{\circ} \mathrm{C}$

69 or

$70^{\circ} \mathrm{C} ; 65^{\circ} \mathrm{C}$ for

$65^{\circ} \mathrm{C}$

\section{Intel Pentium Pro}

Pentium Pro, 256 or $512 \mathrm{~K}$ L2 cache

$85^{\circ} \mathrm{C}$

Pentium Pro, 1MB L2 cache

$80^{\circ} \mathrm{C}$

\section{REFERENCES}

[1] Bhramara P., T. K. K. Reddy, K. Prashanth Reddy (2008) CFD Analysis of Desk Top Heat Sink. Journal of Enhanced Heat Transfer, 15(3) 1-12 (2008)

[2] Culham, J. R. and Muzychka, Y. S. (2000) Optimization of Plate Fin Heat Sinks Using Entropy Generation Minimization, Proc. 7th Intersociety Conf. on Thermal and Thermo-Mechanical Phenomena on Electronics Systems, Vol. 2, pp. 8-15. FLUENT Manual 6.2 Version

[3] Kays, W. M. and London, A. L. (1964) Compact Heat Exchangers, 2nd ed., McGraw-Hill, New York.

[4] Kern, D. Q. and Kraus, A. D. (1972) Extended Surface Heat Transfer, McGraw-Hill, New York.

[5] Kobus, C. J. and Oshio, T. (2005) Development of a Theoretical Model for Predicting the Thermal Performance Characteristics of a Vertical Pin-Fin Array Heat Sink under Combined Forced and Natural Convection with Impinging Flow, Int. J. Heat Mass Transfer, Vol. 48, No. 6, pp. 1053- 1063.

[6] Kobus, C. J. and Oshio, T. (2006) An Experimental and Theoretical Investigation into the Thermal Performance Characteristics of a Staggered Vertical Pin Fin Array Heat Sink with Assisting Mixed Convection in External and In-Duct Flow Configurations, J. Exp. Heat Transfer, Vol. 19, pp. 129-148.

[7] Kothandaraman C.P and Subarhmanyam, Heat and Mass transfer Data book

[8] Lee, S. (1995) Optimum Design and Selection of Heat Sinks, IEEE Trans., Components Packaging Manufacturing Technol., Part A, Vol. 18, No. 4, pp. 812-817. 
[9] Leung, C. W. and Probert, S. D. (1989) Heat-Exchanger Performance: Effect of Orientation, Appl. Energy, Vol. 33 , pp. 235-252.

[10] Minakarni, K, Hisano, K, Iwasaki, H, and Mochizuki, S. (1996) Application of the Pin-Fin Heat Sink to Electronic Equipment [Study on Design Method for Flow-Guide Vanes], Application of CAFJCAD Electronic Systems, ASME, EEP-18, pp. 117-122.

[11] Poulikakos, D. and Bejan, A. (1982) Fin Geometry for Minimum Entropy Generation in Forced Convection, ASME J. Heat Transfer, Vol. 104, pp. 616-623.

[12] Udomsakdigool, C. and Hirunlabh, J. (2007) Design Optimization of a New Hot Heat Sink with a Rectangular Fin Array for Thermoelectric Dehumidifiers, J. Heat Transfer Eng., Vol. 28, No. 7, pp. 645-655.

[13] Yeh, R. H. and Chang, M. (1995) Optimum Longitudinal Convective Fin Arrays, Int. Com. Heat Mass Transfer, Vol. 22, No. 3, pp. 445-460

[14] Bar-Cohen, A. and Jelinek, M. (1985) Optimum Arrays of Longitudinal Rectangular Fins in Convection Heat Transfer, Heat Transfer Eng., Vol. 6, pp. 68-78.

[15] Sparrow, E. M. and Larson, E. D. (1982) Heat Transfer from Pin-Fins Situated in an Oncoming Longitudinal Flow which Turns to Cross Flow, Int. J. Heat Mass Transfer, Vol. 25, No. 5, pp. 603-614. 